\title{
Minireview \\ Targeting BRAF for patients with melanoma
}

\author{
H-T Arkenau*,1,3, R Kefford ${ }^{2}$ and GV Long ${ }^{2,3}$ \\ 'Sarah Cannon Research UK, 93 Harley Street, London WI G 6AD, UK; ${ }^{2}$ Melanoma Institute Australia and Westmead Hospital, University of Sydney, \\ New South Wales, Australia
}

The prognosis of patients with metastatic melanoma is poor and not influenced by systemic therapy with cytotoxic drugs. New targeted agents directed against the RAS-RAF-MEK-ERK pathway show promising activity in early clinical development and particular interest is focused on selective inhibitors of mutant BRAF, which is present in one half of the cases of metastatic melanoma. The majority of patients on early trials of these drugs develop secondary resistance and subsequent disease progression and it is, therefore, critical to understand the underlying escape mechanisms leading to resistance.

British Journal of Cancer (201 I) I 04, 392-398. doi:I0.1038/sj.bjc.6606030 www.bjcancer.com

Published online 7 December 2010

(c) 20I I Cancer Research UK

Keywords: BRAF; BRAF ${ }^{\mathrm{V} 600 E}$; melanoma; PI3K-AKT-mTOR; RAS-RAF-MEK-ERK

\section{MELANOMA: A HETEROGENEOUS DISEASE}

Metastases develop in $10-15 \%$ of patients with cutaneous melanoma and there is no evidence from phase-III trials that systemic treatment prolongs survival, nor is there an effective adjuvant therapy after resection of high risk Stage I-III disease (Thompson et al, 2005). Only 5\% of patients with visceral metastases survive for 2 years (Balch et al, 2001).

Understanding the genetic heterogeneity in melanoma has become increasingly important with the development of therapies aimed at targeting specific genetic aberrations. Of particular importance in melanoma is the mitogen-activated protein kinase (MAPK) pathway, which normally regulates cell growth, proliferation and differentiation (Figure 1). Aberrant activation of the MAPK pathway is present in over $80 \%$ of primary melanomas (Platz et al, 2008), and mutations in proteins along the RAS-RAFMEK-ERK pathway are thought to be mutually exclusive. Such mutations have been documented in all subtypes of melanoma (Curtin et al, 2005), including cutaneous (50-60\% BRAF, 15\% NRAS and $17 \%$ CKIT chronic sun damage), mucosal (11\% BRAF, $5 \%$ NRAS and $21 \%$ CKIT) and uveal (50\% GNAQ) melanomas. The BRAF and NRAS mutations have not been reported in uveal melanoma to date (Populo et al, 2010).

\section{TYPES OF BRAF MUTATIONS}

Constitutively activating somatic missense mutations in BRAF were discovered to be present in a wide variety of human cancers, including papillary thyroid cancer $(39-69 \%)$, cholangiocarcinoma $(22 \%)$, colorectal cancer $(5-12 \%)$ and borderline ovarian cancer (30\%) (Catalogue of Somatic Mutations in Cancer (COSMIC)

\footnotetext{
* Correspondence: Dr H-T Arkenau;

E-mail: tobias.arkenau@sarahcannonresearch.co.uk

${ }^{3}$ These authors contributed equally to this work.

Received 9 July 2010; revised 22 October 20 I0; accepted 9 November 20।0; published online 7 December 2010
}

website). The mutations are either in the activating segment in exon 15 or the glycine-rich loop (P-loop) in exon 11 of the kinase domain of the BRAF protein (Figure 2). The point mutation in DNA $(1799 \mathrm{~T} \rightarrow \mathrm{A})$ resulting in a single amino-acid substitution at Valine 600 to Glutamic acid in the activating segment (V600E, previously known as $\mathrm{V} 599 \mathrm{E}$ ) is the most common change, and is found in $80 \%$ of the mutated tumours (Davies et al, 2002). This is distinct from the $\mathrm{CC} \rightarrow \mathrm{TT}$ or $\mathrm{C} \rightarrow \mathrm{T}$ changes associated with ultraviolet light exposure in non-melanoma skin cancers. BRAF V600E results in elevated kinase activity compared with BRAF wild type and stimulated phosphorylation of downstream endogenous ERK (Dhomen and Marais, 2009).

Today more than 75 somatic mutations in the BRAF gene have been identified in melanoma, and all mutations at V600 in Exon 15 constitutively activate BRAF (Figure 2). In BRAF mutant melanoma, $74-90 \%$ are V600E (Platz et al, 2008) and $16-29 \%$ are V600K mutations (Thomas, 2006; Long et al, 2010). One hypothesis for the mechanism of uncontrolled activation is the increased exposure of the activation segment for interaction when a small hydrophobic amino acid at 600 (Valine) is switched to a hydrophilic residue. Normally, the RAF kinase domain in the inactive conformation is hidden in a hydrophobic pocket (Wan et al, 2004). A small number of mutations have reduced kinase activity compared with wild type, for example, G465E, G465V, D593V and G595R, but cause increased ERK activation, possibly via binding and activation of CRAF (Houben et al, 2004; Wan et al, 2004).

\section{PROGNOSIS OF BRAF MUTATION IN METASTATIC MELANOMA}

The frequency of BRAF mutation in primary melanomas ranges from 36 to 45\% (Curtin et al, 2005; Liu et al, 2007; Thomas et al, 2007) and $42-55 \%$ in metastatic melanoma (Houben et al, 2004; Ugurel et al, 2007; Long et al, 2010). The presence of a BRAF mutation in early melanoma shows no association with diseasefree interval or overall survival (Shinozaki et al, 2004). In contrast, the presence of a BRAF mutation in metastatic melanoma is 


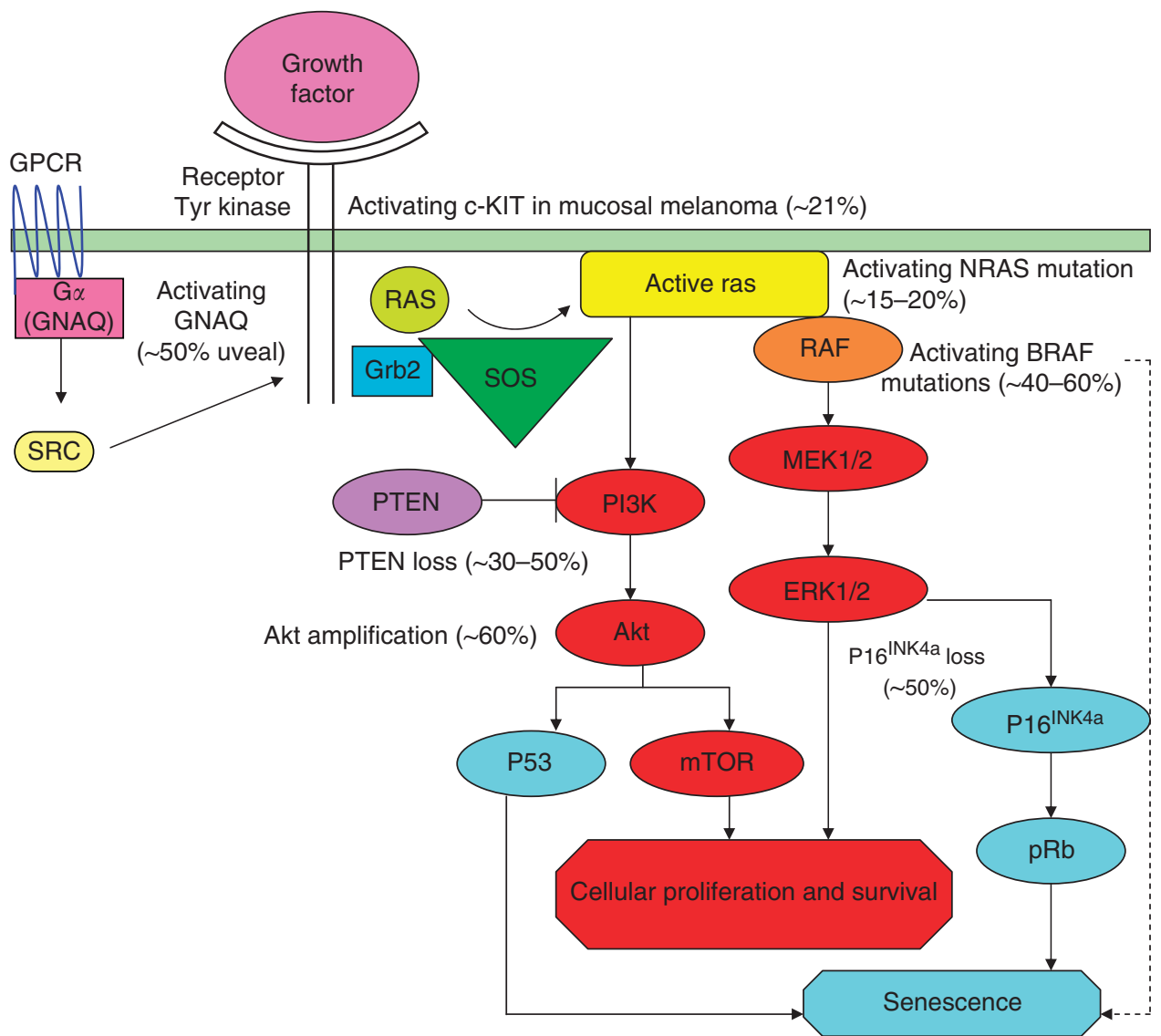

Figure I The MAPK pathway activation in melanoma. Oncogenic NRAS, BRAF, GNAQ and CKIT signal through the MAPK pathway. Oncogenic NRAS also induces the phosphatidylinositol-3' kinase (PI3K) cascade. MAPK signalling can lead to proliferation in transformed cells, but also induces a potent form of growth arrest, known as senescence in normal melanocytes. The approximate proportion of melanomas with mutations are shown. GPCR $=\mathrm{G}$-protein coupled receptor.

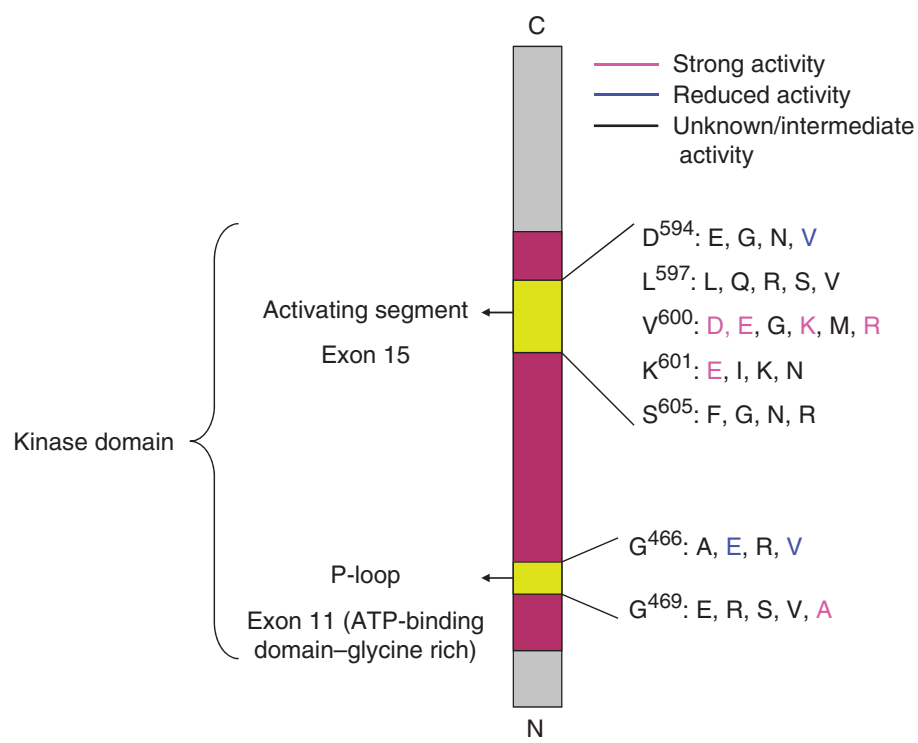

Figure 2 Common types of BRAF mutations in melanoma (Wan et al, 2004).

associated with a poorer survival from time of first metastasis (Long et al, 2010) or time from first resected metastasis (Houben et al, 2004), although not consistently observed in smaller studies (Ugurel et al, 2007).

\section{RATIONALE FOR BRAF INHIBITION IN MELANOMA}

Advanced melanomas often have multiple genetic defects affecting diverse biochemical pathways. It was, therefore, surprising that 
those with activating BRAF mutations displayed the hallmarks of oncogene addiction. When this single oncogenic alteration was targeted in melanoma cell lines with specific inhibitory nucleic acids or chemical RAF inhibitors, the cell lines displayed growth arrest and induction of apoptosis (Calipel et al, 2003). The behaviour of mutant BRAF melanomas in murine xenograft models supported these preclinical findings and confirmed mutant $\mathrm{BRAF}$ as an attractive target for melanoma therapy, particularly as it occurs in at least half the tumour population, and does not occur in normal cells. In addition, its serine/threonine kinase domain was amenable to the rational design of selective inhibitors.

\section{EARLY CLINICAL DATA OF RAF INHIBITORS IN MELANOMA PATIENTS}

The first RAF kinase inhibitor entering early clinical trials was the oral diphenyl urea, sorafenib (Bay 43-9006). Sorafenib has potent RAF isoform kinase inhibitor activities (CRAF ( IC $_{50} 6 \mathrm{~nm}$ ) $>$ wild type (wt) BRAF ( IC $\left._{50} 22 \mathrm{nM}\right)>$ mutant BRAF ${ }^{\mathrm{V} 599 \mathrm{E}}\left(\mathrm{IC}_{50} 38 \mathrm{nM}\right)$ ), but was also found to have a much broader inhibitory profile, including kinases of the vascular endothelial growth factor receptor 2 and 3 (VEGFR-2 (IC $5090 \mathrm{nm)}$ ) and VEGFR-3 ( $\mathrm{IC}_{50}$ $20 \mathrm{nM})$ ), the platelet-derived growth factor receptor- $\beta\left(\mathrm{IC}_{50} 57 \mathrm{nM}\right)$, Flt-3 ( $\left.\mathrm{IC}_{50} 58 \mathrm{nM}\right)$ and c-Kit ( $\left.\mathrm{IC}_{50} 68 \mathrm{~nm}\right)$.

In human xenograft models sorafenib resulted in prolonged growth stabilisation rather than tumour response, perhaps forewarning the negligible clinical activity in melanoma patients who were treated within a discontinuation phase-II trial
(Karasarides et al, 2004; Eisen et al, 2006). These results raised questions about the in human BRAF inhibitory activity of sorafenib and raised scepticism about the relevance of mutant BRAF as a target in melanoma. Activity of the drug in renal cell and hepatocellular carcinoma has since been attributed to promiscuous inhibitory effects on receptor tyrosine kinases, including VEGFR, PDGFR and cKIT.

Further research led to the development of second generation more selective RAF inhibitors, which are currently in clinical trials (Table 1).

XL281 (famotidine) is an orally administered inhibitor of the wt BRAF ( $\left.\mathrm{IC}_{50} 4.5 \mathrm{~nm}\right)$, CRAF ( $\left.\mathrm{IC}_{50} 2.5 \mathrm{~nm}\right)$ and mutant $\mathrm{BRAF}^{\mathrm{V} 600 \mathrm{E}}\left(\mathrm{IC}_{50} 6 \mathrm{nM}\right)$ kinases and demonstrated potent inhibitory effect in a variety of human xenograft models. The phase-I study of XL281 (NCT00451880) in an unselected patient population showed prolonged disease stabilisation in two patients with $\mathrm{BRAF}^{\mathrm{V} 600 \mathrm{E}}$ mutant papillary thyroid cancer ( $>15$ and 17 months, respectively) and some minor responses in nine patients with colorectal, ovarian and non-small-cell lung cancer. Overall XL281 was well tolerated with acceptable rates of grade 3/4 nausea, vomiting and diarrhoea (Schwartz et al, 2009). Currently, a three-arm dose expansion part is expected to recruit a total of 180 patients, including patients with melanoma, papillary thyroid and colorectal and non-small-cell lung cancer. Results of an ongoing melanoma phase-I/II trial (RAF265-MEL01; wt BRAF and BRAF mutant patients included) are awaited.

PLX4032 (RO 5185426) is an ATP competitive, orally administered BRAF inhibitor (wt BRAF IC $_{50} 100 \mathrm{nM}$ ) with high selectivity

Table I Clinical development of RAF kinase inhibitors in patients with advanced melanoma

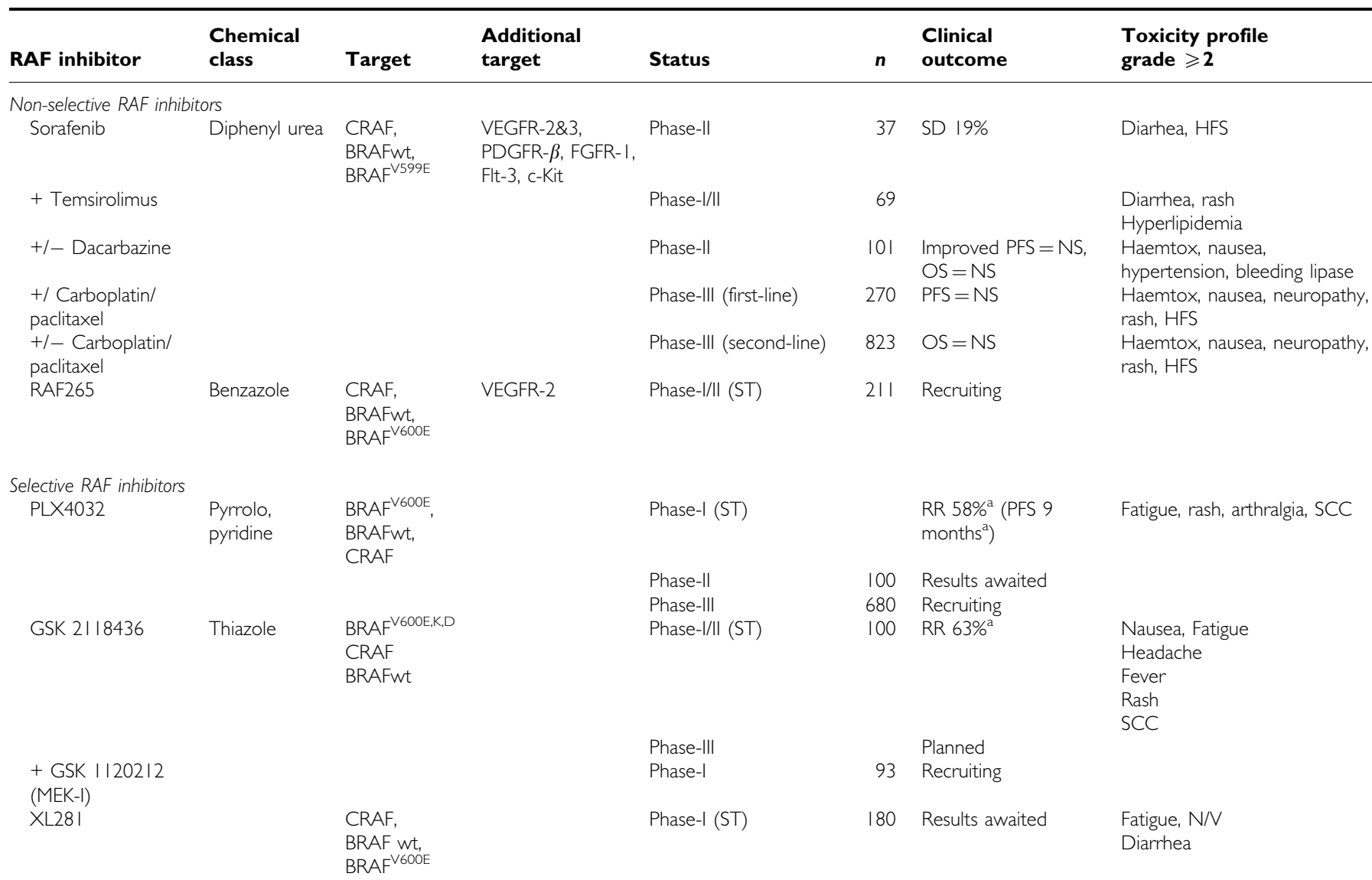

Abbreviations: HFS = hand-foot syndrome; NS = not significant; OS = overall survival; PFS = progression-free survival; RR = response rate; SCC=squamous cell carcinoma; $\mathrm{SD}=$ stable disease; $\mathrm{ST}=$ solid tumour. ${ }^{\mathrm{a}} \mathrm{At}$ the recommended phase-ll dose level in melanoma subgroup. 
for the mutant allele (BRAF ${ }^{\mathrm{V} 600 \mathrm{E}} \mathrm{IC}_{50} 31 \mathrm{nM}$ ) and has shown selective tumour suppression in mutant BRAF cell lines and xenograft models. In a phase-I clinical trial enriched for patients with mutant BRAF metastatic melanoma 11/16 (68\%) achieved partial response (PR) and four patients had minor responses leading to a progression-free survival (PFS) of 8-9 months (Flaherty et al, 2009). The dose expansion cohort enroled a selected group of $\mathrm{BRAF}^{\mathrm{V} 600 \mathrm{E}}$ melanoma patients $(n=32)$ at the MTD dose level of $960 \mathrm{mg}$ twice daily (Chapman et al, 2009). In this group, a total of 26 patients (81\%) had response (two CR and 24 PR). Overall PLX4032 was well tolerated with mild nausea and vomiting, skin rash and diarrhoea, but $21 \%$ of the patients on active doses developed cutaneous neoplasms, including keratoacanthoma (KA), low-grade squamous cell carcinoma (SCC) and verrucal-like lesions. These lesions occurred within 8-12 weeks from treatment start and were resectable (Flaherty et al, 2010a, b). On the basis of these promising results, a phase-II trial (BRIM 2, NCT00949702) is now fully accrued and a phase-III trial (BRIM3, NCT01006980) comparing PLX4032 to standard chemotherapy with the alkylating agent dacarbazine in untreated patients with $\mathrm{BRAF}^{\mathrm{V} 600 \mathrm{E}}$ mutant metastatic melanoma is underway.

GSK 2118436 is an ATP competitive, reversible inhibitor of the mutant $\mathrm{BRAF}^{\mathrm{V} 600 \mathrm{E} / \mathrm{K} / \mathrm{D}}\left(\mathrm{IC}_{50} 0.5,0.6,1.9 \mathrm{nM}\right.$, respectively), wt BRAF ( $\mathrm{IC}_{50} 12 \mathrm{nM}$ ) and CRAF ( $\mathrm{IC}_{50} 5 \mathrm{~nm}$ ) kinases with promising preclinical efficacy data in melanoma. A phase-I trial (NCT00880321) of this oral compound enroled $>100$ patients with BRAF mutations (primarily melanoma patients) (Kefford et al, 2010). Overall GSK 2118436 showed good tolerability with grade $1 / 2$ nausea, fatigue, fever, headaches and skin rash as the main side effects. In total, $9 \%$ of the patients developed cutaneous neoplasms, including low-grade SCC that occurred between weeks 2 and 14. Preliminary pharmacodynamic data showed dosedependent phospho-ERK inhibition and a correlation with clinical response. Clinical responses (63\% PR) were seen at the recommended phase-II dose (150 mg twice daily), with responses in lung, liver, bone and brain metastases. Importantly, these responses were not only seen in patients with $\mathrm{BRAF}^{\mathrm{V} 600 \mathrm{E}}$ but also in $\mathrm{BRAF}^{\mathrm{V} 600 \mathrm{~K}}$ and $\mathrm{BRAF}^{\mathrm{V} 600 \mathrm{G}}$ mutations, and possibly shows the wider range of activity of selective BRAF inhibitors that are not limited only to BRAF ${ }^{600 \mathrm{E}}$-mutant tumours. These findings were also supported by a recent case report of the BRAF inhibitor PLX4032 in a BRAF ${ }^{\mathrm{V} 600 \mathrm{~K}}$ mutant patient (Rubinstein et al, 2010).

A phase-II study of GSK 2118436 is currently underway as salvage therapy in mutant BRAF metastatic melanoma and a phase-I study has commenced of GSK 2118436 in combination with the MEK-inhibitor, GSK1120212, (NCT01072175) in BRAF mutant melanoma patients, a strategy of tandem MAPK inhibition.

Other selective B-RAF inhibitors are currently in preclinical and early clinical development and include GDC-0879, ARQ736 and AZ628, among others.

\section{SPECIFIC SIDE EFFECTS OF SELECTIVE RAF INHIBITORS}

Selective RAF inhibitors display good tolerability with infrequent severe toxicities. Among the common grade 1-2 adverse events are skin changes $(50-70 \%)$, fatigue $(30-50 \%)$, diarrhoea $(10-30 \%)$ and nausea $(10-20 \%)$. In the GSK 2118436 phase-I trial, $29 \%$ of patients reported mild grade $1 / 2$ headaches and a possible cytokine-related fever in $37 \%$ of the patients.

Most concerning was the development of cutaneous lesions, including KA and SCC in 15-30\% of patients on the GSK 2118436 and the PLX4032 studies (Flaherty et al, 2010a,b; Kefford et al, 2010). The biology and natural history of these lesions, in comparison to their spontaneouas counterparts is unknown, and no systemic spread has been reported to date. One possibility to explain the underlying mechanism could be an exacerbation of upstream RAS mutations in pre-existing skin lesions. RAS mutations occur in approximately $15 \%$ of SCCs and, under these conditions, alterations in downstream dimerisation of BRAF by selective BRAF inhibitors could lead to paradoxical activation of the MAPK pathway in squamous cells.

Notably, the phenomenon of paradoxical activation of the MAP kinase pathway has been reported with mutant-selective BRAF inhibitors under certain conditions (Hatzivassiliou et al, 2010; Heidorn et al, 2010; Poulikakos et al, 2010). Although inhibition of MEK and ERK phosphorylation was achieved in $\mathrm{BRAF}^{\mathrm{V} 600 \mathrm{E} / \mathrm{K}}$ mutant melanoma, significantly increased tumour growth was seen in BRAF wild-type melanomas with upstream RAS mutations. It is proposed that in BRAF wild-type tumours BRAF signalling is usually inactivated via BRAF-induced autophosphorylation, but this self-inhibitory process is interrupted by selective BRAF inhibition. Subsequently, in a RAS-dependent manner BRAF is recruited to the plasma membrane and hyper-activates CRAF, which in turn signals downstream to MEK and ERK. This phenomenon was not observed with non-selective RAF inhibitors, probably because of the promiscuous pan-RAF inhibitory effects. Similar mechanisms are thought to underlie the induction of pre-malignant and malignant changes in keratinocytes. Some of the skin changes seen in patients on selective RAF inhibitors mimic those seen in patients with hereditary gain-of-function mutations in the MAP kinase pathway (Roberts et al, 2006), and the frequent induction of SCCs may be due to the same process in keratinocytes carrying RAS mutations.

These findings have important clinical implications, and highlight the need for genotyping tumours before treatment with selective RAF inhibitors and screening for secondary tumours.

\section{MECHANISM OF RESISTANCE}

Similar to other kinase inhibitors (i.e., erlotinib and imatinib), selective RAF inhibitors can lead to drastic and impressive early tumour responses in humans, which may be of short duration in some patients. Approximately $20 \%$ of patients with mutant BRAF melanoma show no response, and most patients relapse, with a median PFS of 8-9 months.

In preclinical studies, a subset of resistant $\mathrm{BRAF}^{\mathrm{V} 600 \mathrm{E}}$ mutant cell lines demonstrated increased CRAF signalling via BRAF/ CRAF heterodimerisation and resulted in a shift from B-RAF to CRAF dependency. In addition post-transcriptional elevation of CRAF protein levels are thought to decrease intracellular bioavailability of the selective RAF inhibitor AZ628 and subsequent development of resistance (Montagut et al, 2008).

Amplification of the CCND1 gene resulting in cyclin D1 overexpression has been reported to be present in $17 \%$ of mutant $\mathrm{BRAF}^{\mathrm{V} 600 \mathrm{E}}$ melanomas with independent stimulatory effects on cell-cycle progression via CDK4 (Smalley et al, 2008). Furthermore, point mutations of the downstream kinase isoform MEK1 (P124L, $\mathrm{P} 124 \mathrm{~S}$ and Q56P), have resulted in changes of the allosteric drugbinding pocket within helices $\mathrm{A}$ and $\mathrm{C}$ leading to sub-optimal drug binding of the selective RAF inhibitor PLX4720 in mutant melanoma cells in cell culture and in vivo (Emery et al, 2009).

\section{RELEVANCE OF THE AKT PATHWAY}

Preclinical studies have demonstrated a close interconnection of the RAS-RAF-MEK-ERK and the PI3K-AKT-mTOR signalling pathways, with complex inter-related feedback loops. For example, NRAS is mutated in about $15 \%$ of melanoma and can activate both the signalling pathways. Although BRAF and NRAS mutations are mutually exclusive in the majority of melanomas, dual pathway signalling is also frequently seen in melanoma through functional loss (deletion, silencing and/or mutation) of the tumour suppressor gene PTEN (Figure 1). Both, genetic changes are seen in 
approximately $20 \%$ of melanomas (Dankort et al, 2009). As a major regulator of the PI3K-AKT axis PTEN loss leads to activation of the AKT/mTOR pathway and, via feedback loops, to phosphorylation of MEK and ERK (Tsao et al, 2004).

AKT has a central role in regulating apoptosis and overexpression (via amplification or mutation) of the isoform AKT3 correlates with tumour progression. Recent preclinical studies have shown that inhibitors of PI3K and AKT3 increased apoptosis and stimulated tumour regression (Cheung et al, 2008). In $\mathrm{BRAF}^{\mathrm{V} 600 \mathrm{E}}$ mutant cells, AKT activation was required for melanoma initiation, demonstrating the inter-dependence of these two pathways in melanoma.

Downstream of AKT, increased signalling via mTOR regulates translation of pro-proliferative proteins. In preclinical studies, the mTOR inhibitor temsirolimus reversed these effects, however, this was not reproducible in clinical melanoma trials (Margolin et al, 2005). These findings could be in part explained by the dual signalling complex of mTOR, including TORC 1 and TORC2. Although temsirolimus (and other rapalogs) inhibits mTOR via TORC1, the uninhibited TORC2 complex continues to stimulate AKT through phosphorylation (Feldman and Shokat, 2011). Trials of dual TORC1 and TORC2 inhibitors are currently in phase-I studies to inhibit both AKT and mTOR signalling.

\section{RATIONALLY DESIGNED COMBINATION DRUG THERAPY}

There is increasing evidence that combination therapies targeting the RAS-RAF-MEK-ERK and the PI3K-AKT-mTOR may be more effective than single-agent therapies. For example in threedimensional cell cultures of BRAF mutant melanoma the combination of BRAF and AKT3 directed siRNAs demonstrated significantly higher reduction of tumour growth compared with weak growth inhibition by single-agent administration (Cheung et al, 2008). These findings were confirmed in a melanoma xenograft model (Bedogni et al, 2006). There is evidence of synergism when MEK and PI3K inhibitors are combined and increased apoptotic activity was also demonstrated with a combination of the mTOR inhibitor rapamycin and sorafenib or an MEK inhibitor (Lasithiotakis et al, 2008). In contrast to singleagent activity, these combinations resulted in complete downregulation of the anti-apoptotic proteins Bcl-2 and Mcl-1.

Preclinical studies have also shown a synergism between BRAF and MEK inhibitors, with significantly increased apoptosis and prolonged phospho-ERK inhibition compared with BRAF inhibition alone (Paraiso et al, 2010). This hypothesis is currently tested in two phase-I studies. The study, NCT01072175, combines the selective RAF inhibitor, GSK 2118436, and MEK inhibitor, GSK1120212, in patients with BRAF mutant metastatic melanoma and the study, NCT01037127, explores the efficacy of the MEK inhibitor, GSK1120212, in patients with BRAF mutant tumours who previously failed a selective BRAF inhibitor. The design of these trials rests on the observation that MEK activation persists in melanoma cell lines that develop resistance to BRAF inhibition (Montagut et al, 2008; Smalley et al, 2008).

Currently, clinical trials of selective RAF inhibitors in combination with other kinase inhibitors, such as MEK, mTOR, PI3K or AKT are underway or planned. Issues related to these combinations include overlapping or synergistic toxicities and mechanisms of resistance.

\section{COMBINATIONS OF RAF INHIBITORS WITH CHEMOTHERAPY}

Although the combination of sorafenib and dacarbazine resulted in $24 \%$ response rates compared with $12 \%$ with dacarbazine alone, there was no effect on the primary endpoint of PFS (McDermott et al, 2008). Two large phase-III trials of sorafenib in combination with carboplatin/paclitaxel in chemotherapy-naive (Flaherty et al, 2010a,b) and pre-treated (Hauschild et al, 2009) patients with BRAF undefined metastatic melanoma did not meet the primary endpoint of improved overall survival.

Whether combinations of selective RAF inhibitors in patients with BRAF mutant melanoma will result in better outcomes remains to be investigated.

Moreover, there is compelling evidence to combine chemotherapy with other inhibitors of the RAS-RAF-MEK-ERK and PI3K-AKT-mTOR pathways.

For example, preclinical data suggest that taxane resistance may be due to increased MEK signalling resulting in anti-apoptotic changes (Haass et al, 2009). On the basis of these results a phase-II trial of a taxane-based chemotherapy plus the MEK inhibitor AZD 6244 is in preparation and patients will be randomised according to their BRAF/NRAS mutational status.

The commonly used chemotherapy agents, cisplatin and temozolomide, have the potential to trigger pro-survival and anti-apoptotic effects by activating the AKT signalling pathway (Sinnberg et al, 2009). Interestingly, AKT inhibitors reverse these effects in preclinical studies by reducing the anti-apoptotic proteins Bcl-2 and Mcl-1. On this basis, clinical trials of combinations of $\mathrm{PI} 3 \mathrm{~K} / \mathrm{AKT} / \mathrm{mTOR}$ inhibitors with temozolomide or cisplatin are underway.

\section{OTHER COMBINATIONS OF SELECTIVE RAF INHIBITORS}

Heat-shock protein 90 (HSP90) is a molecular chaperone responsible for degradation, stabilisation and activation of a variety of proteins, including HER2, CRAF, BRAF, AKT and MET. In melanoma, HSP90 stabilises CRAF and ARAF and is required for the activity of $\mathrm{BRAF}^{\mathrm{V} 600 \mathrm{E}}$. In patients with mutant BRAF melanoma a combination of a selective RAF inhibitor with an HSP90 inhibitor may, therefore, inhibit multiple pathways involved in resistance. This rationale is supported by preclinical data of the HSP90 inhibitor geldanamycin (Banerji, 2009), which promotes the degradation of CRAF, a protein known to be commonly over-expressed in resistant BRAF mutant cells.

Epigenetic changes via DNA hyper-methylation or changes in DNA remodelling have an important role in cancer development. For example, epigenetic silencing is a frequent mechanism of functional loss of the tumour suppressor gene PTEN in melanoma. Agents, such as the histone deacetylating inhibitors (HDACIs), may restore the tumour supressor function by reversing the effects of epigenetic silencing (Kuwajima et al, 2007). Current single-agent HDACI trials show promising results in melanoma patients (Ryan et al, 2005) and combinations with selective BRAF inhibitors are planned.

\section{CONCLUSION}

Clinical trials of new selective RAF inhibitors are currently recruiting, and two recent 'proof of concept' phase-I studies have shown activity in metastatic melanoma, a disease notoriously resistant to systemic treatment.

Despite this progress there are important questions to be addressed in current and planned clinical trials. These include the impact of selective BRAF inhibitors on overall survival and quality of life, the identification of biomarkers of early resistance and relapse, the selection and scheduling of drugs to combine with BRAF inhibitors, and the mechanism and prevention of adverse events, such as SCC. 


\section{REFERENCES}

Balch CM, Soong SJ, Gershenwald JE, Thompson JF, Reintgen DS, Cascinelli $\mathrm{N}$, Urist M, McMasters KM, Ross MI, Kirkwood JM, Atkins MB, Thompson JA, Coit DG, Byrd D, Desmond R, Zhang Y, Liu PY, Lyman GH, Morabito A (2001) Prognostic Factors Analysis of 17600 Melanoma Patients: validation of the American Joint Committee on Cancer Melanoma Staging System. J Clin Oncol 19(16): 3622-3634

Banerji U (2009) Heat shock protein 90 as a drug target: some like it hot. Clin Cancer Res 15(1): 9-14

Bedogni B, Welford SM, Kwan AC, Ranger-Moore J, Saboda K, Powell MB (2006) Inhibition of phosphatidylinositol-3-kinase and mitogenactivated protein kinase $1 / 2$ prevents melanoma development and promotes melanoma regression in the transgenic TPRas mouse model. Mol Cancer Ther 5(5): 1136-1144

Calipel A, Lefevre G, Pouponnot C, Mouriaux F, Eychene A, Mascarelli F (2003) Mutation in B-Raf in human choroidal melanoma cell lines mediates cell proliferation and transformation through the MEK/ERK pathway. J Biol Chem 278: 42409-42418

Catalogue of Somatic Mutations in Cancer (COSMIC) website. http://www. sanger.ac.uk/genetics/CGP/cosmic/ : Wellcome Trust Sanger Institute

Chapman P, Puzanov I, Sosman J, Kim K, Ribas A, McArthur G, Lee R, Grippo J, Nolop K, Flaherty K (2009) Early efficacy signal demonstrated in advanced melanoma in a phase I trial of the oncogenic BRAF-selective inhibitor PLX4032. Eur J Cancer 7(3): 5 (abstract 6LB)

Cheung M, Sharma A, Madhunapantula AV, Robertson G (2008) Akt3 and mutant $\mathrm{V} 600{ }^{\mathrm{E}} \mathrm{BRAF}$ cooperate to promote early melanoma development. Cancer Res 68(9): 3429-3439

Curtin JA, Fridlyand J, Kageshita T, Patel HN, Busam KJ, Kutzner H, Cho KH, Aiba S, Bröcker EB, LeBoit PE, Pinkel D, Bastian BC (2005) Distinct sets of genetic alterations in melanoma. $N$ Engl J Med 353(20): $2135-2147$

Dankort D, Curley DP, Cartlidge RA, Nelson B, Karnezis AN, Damsky WE, You MJ, DePhino RA, McMahon M, Bosenberg M (2009) BRAFv600E cooperates with Pten silencing to elicit metastatic melanoma. Nat Genet 41(5): $544-552$

Davies H, Bignell GR, Cox C, Stephens P, Edkins S, Clegg S, Teague J, Woffendin H, Garnett MJ, Bottomley W, Davis N, Dicks E, Ewing R, Floyd Y, Gray K, Hall S, Hawes R, Hughes J, Kosmidou V, Menzies A, Mould C, Parker A, Stevens C, Watt S, Hooper S, Wilson R, Jayatilake H, Gusterson BA, Cooper C, Shipley J, Hargrave D, Pritchard-Jones K, Maitland N, Chenevix-Trench G, Riggins GJ, Bigner DD, Palmieri G, Cossu A, Flanagan A, Nicholson A, Ho JW, Leung SY, Yuen ST, Weber BL, Seigler HF, Darrow TL, Paterson H, Marais R, Marshall CJ, Wooster R, Stratton MR, Futreal PA (2002) Mutations of the BRAF gene in human cancer. Nature 417(6892): $949-954$

Dhomen N, Marais R (2009) BRAF signaling and targeted therapies in melanoma. Hematol Oncol Clin of North Am 23(3): 529-545

Eisen T, Ahmad T, Flaherty KT, Gore M, Kaye S, Marais R, Gibbens I, Hackett S, James M, Schuchter LM, Nathanson KL, Xia C, Simantov R, Schwartz B, Poulin-Costello M, O’Dwyer PJ, Ratain MJ (2006) Sorafenib in advanced melanoma: a Phase-II randomised dicontiuation trial analysis. Br J Cancer 5(2): 120-130

Emery CM, Vijayendran KG, Zipser MC, Sawyer AM, Niu L, Kim JJ, Hatton C, Chopra R, Oberholzer PA, Karpova MB, MacConaill LE, Zhang J, Gray NS, Sellers WR, Dummer R, Garraway LA (2009) MEK1 mutations confer resistance to MEK and B-RAF inhibition. Proc Natl Acad Sci USA 106(48): 20411-20416

Feldman ME, Shokat KM (2011) New Inhibitors of the PI3K-Akt-mTOR Pathway: Insights into mTOR Signaling from a New Generation of Tor Kinase Domain Inhibitors (TORKinibs). Curr Top Microbiol Immunol 347: $241-262$

Flaherty K, Puzanov I, Sosman J, Kim K, Ribas A, McArthur G, Lee RJ, Grippo JF, Nolop K, Chapman P (2009) Phase I study of PLX4032: proof of concept for V600E BRAF mutation as a therapeutic target in human cancer. J Clin Oncol 27: 15s (abstract 9000)

Flaherty KT, Lee SJ, Schuchter LM, Flaherty LE, Wright JJ, Leming PD, Flaherty LE, Wright JJ, Leming PD, Kirkwood JM (2010a) Final results of E2603: a double blind, randomized phase-III trial comparing carboplatin/paclitaxel with or without sorafenib in metastatic melanoma. J Clin Oncol 28: 5s (abstract 8511)

Flaherty KT, Puzanov I, Kim KB, Ribas A, McArthur GA, Sosman JA, O'Dwyer PJ, Lee RJ, Grippo JF, Nolop K, Chapman PB (2010b) Inhibition of mutated, activated BRAF in metastatic melanoma. $N$ Engl $J$ Med 363(9): $809-819$
Haass NK, Sproesser K, Nguyen TK, Contractor R, Medina CA, Nathanson KL, Herlyn M, Smalley KS (2009) The mitogen activated protein/ extracellular signal-regulated kinase kinase inhibitor AZD6244 (ARRY142886) induces growth arrest in melanoma cells and tumor regression when combined with docetaxel. Clin Cancer Res 15(12): 4147-4156

Hatzivassiliou G, Song K, Yen I, Brandhuber BJ, Anderson DJ, Alvarado R, Ludlam MJ, Stokoe D, Gloor SL, Vigers G, Morales T, Aliagas I, Liu B, Sideris S, Hoeflich KP, Jaiswal BS, Seshagiri S, Koeppen H, Belvin M, Friedman LS, Malek S (2010) RAF inhibitors prime wild-type RAF to activate the MAPK pathway and enhance growth. Nature 464(7287): $431-435$

Hauschild A, Agarwala SS, Trefzer U, Hogg D, Robert C, Hersey P, Eggermont A, Grabbe S, Gonzalez R, Gille J, Peschel C, Schadendorf D, Garbe C, O'Day S, Daud A, White JM, Xia C, Patel K, Kirkwood JM, Keilholz U (2009) Results of a phase-III, randomized, placebo-controlled study of sorafenib in combination with carboplatin and paclitaxcel as second-line treatment in patients with unresectable stage III or stage IV melanoma. J Clin Oncol 27(17): 2823-2830

Heidorn SJ, Milagre C, Whittaker S, Nourry A, Niculescu-Duvas I, Dhomen N, Hussain J, Reis-Filho JS, Springer CJ, Pritchard C, Marais R (2010) Kinase-Dead BRAF and Oncogenic RAS cooperate to drive tumor progression through CRAF. Cell 140(2): 209-221

Houben R, Becker JC, Kappel A, Terheyden P, Bröcker EB, Goetz R, Rapp UR (2004) Constitutive activation of the Ras-Raf signaling pathway in metastatic melanoma is associated with poor prognosis. $J$ Carcinog 3(1): 6

Karasarides M, Chiloeches A, Hayward R, Niculescu-Duvaz D, Scanlon I, Friedlos F, Ogilvie L, Hedley D, Martin J, Marshall CJ, Springer CJ, Marais R (2004) B-RAF is a therapeutic target in melanoma. Oncogene 23: $6292-6298$

Kefford R, Arkenau H, Brown MP, Millward M, Infante JR, Long GV, Ouellet D, Curtis M, Lebowitz PF, Falchook GS (2010) Phase I/II study of GSK2118436, a selective inhibitor of oncogenic mutant BRAF kinase, in patients with metastatic melanoma and other solid tumors. J Clin Oncol 28: 15 s (abstract 8503)

Kuwajima A, Iwashita J, Murata J, Abe T (2007) The histone deacetylase inhibitor butyrate inhibits melanoma cell invasion of matrigel. Anticancer Res 27(6B): 4163-4169

Lasithiotakis KG, Sinnberg TW, Schittek B, Flaherty KT, Kulms D, Maczey E, Garbe C, Meier FE (2008) Combined inhibition of MAPK and mTOR signaling inhibits growth, induces cell death, and abbrogates invasive growth of melanoma cells. J Invest Dermatol 128(8): $2013-2023$

Liu W, Kelly JW, Trivett M, Murray WK, Dowling JP, Wolfe R, Mason G, Magee J, Angel C, Dobrovic A, McArthur GA (2007) Distinct clinical and pathological features are associated with the BRAFT1799A(V600E) mutation in primary melanoma. J Invest Dermatol 127(4): 900-905

Long GV, Menzies AM, Nagrial AM, Haydu LL, Hamilton AL, Mann G, Hughes TM, Thompson JF, Scolyer RA, Kefford R (2010) Clinicopathologic correlates of BRAF mutation status in 207 consecutive patients with metastatic melanoma. J Clin Oncol 28: 15s (abstract 8548)

Margolin K, Longmate J, Baratta T, Synold T, Christensen S, Weber J, Gajewski T, Quirt I, Doroshow JH (2005) CCI-779 in metastatic melanoma: a phase-II trial of the California Cancer Consortium. Cancer 104: 1045 - 1048

McDermott DF, Sosman JA, Gonzalez R, Hodi FS, Linette GP, Richards J, Jakub JW, Beeram M, Tarantolo S, Agarwala S, Frenette G, Puzanov I, Cranmer L, Lewis K, Kirkwood J, White JM, Xia C, Patel K, Hersh E (2008) Double-blind randomized phase II study of the combination of sorafenib and dacarbazine in patients with advanced melanoma: a report from the 11715 study group. J Clin Oncol 26(13): 2178-2185

Montagut C, Sharma SV, Shioda T, McDermott U, Ulman M, Ulkus LE, Dias-Santagata D, Stubbs H, Lee DY, Singh A, Drew L, Haber DA, Settleman J (2008) Elevated CRAF as a potential mechanism of acquired resistance to BRAF inhibition in melanoma. Cancer Res 68(12): $4853-4861$

Paraiso KH, Fedorenko IV, Cantini LP, Munko AC, Hall M, Sondak VK, Messina JL, Flaherty KT, Smalley KS (2010) Recovery of phospho-ERK activity allows melanoma cells to escape from BRAF inhibitor therapy. Br J Cancer 102(12): 1724-1730

Platz A, Egyhazi S, Ringborg U, Hansson J (2008) Human cutaneous melanoma; a review of NRAS and BRAF mutation frequencies in relation to histogenetic subclass and body site. Mol Oncol 1: 395-405 
Populo H, Soares P, Rocha AS, Silva P, Lopes JM (2010) Evaluation of the mTOR pathway in ocular (uvea and conjunctiva) melanoma. Melanoma Res 20(2): $107-117$

Poulikakos PI, Zhang C, Bollag G, Shokat KM, Rosen N (2010) RAF inhibitors transactivate RAF dimers and ERK signalling in cells with wild-type BRAF. Nature 464(7287): 427-430

Roberts A, Allanson J, Jadico SK, Kavamura MI, Noonan J, Opitz JM, Young T, Neri G (2006) The cardiofaciocutaneous syndrome. J Med Genet 43: $833-842$

Rubinstein JC, Sznol M, Pavlick AC, Ariyan S, Cheng E, Bacchiocchi A, Kluger HM, Narayan D, Halaban R (2010) J Transl Med 8: 67

Ryan QC, Headlee D, Acharya M, Sparreboom A, Trepel JB, Ye J, Figg WD, Hwang K, Chung EJ, Murgo A, Melillo G, Elsayed Y, Monga M, Kalnitskiy M, Zwiebel J, Sauaville EA (2005) Phase-I and pahrmakokinetic study of MS-275, a histone deacetylase inhibitor, in patients with advanced and refractory solid tumors or lymphoma. J Clin Oncol 23(17): $3912-3922$

Sinnberg T, Lasithiotakis K, Niessner H, Schittek B, Flaherty KT, Kulms D, Maczey E, Campos M, Gogel J, Garbe C, Meier F (2009) Inhibition of PI3K-AKT-mTOR signaling sensitizes melanoma cells to cisplatin and temozolomide. J Invest Dermatol 129(6): 1500 - 1503

Shinozaki M, Fujimoto A, Morton DL, Hoon DSB (2004) Incidence of BRAF Oncogene Mutation and Clinical Relevance for Primary Cutaneous Melanomas. Clin Cancer Res 10(5): 1753-1755

Smalley KS, Lioni M, Dalla Palma M, Xiao M, Desai B, Egyhazi S, Hansson J, Wu H, King AJ, Van Belle P, Elder DE, Flaherty KT, Herlyn M, Nathanson KL (2008) Increased cyclin D1 expression can mediate BRAF inhibitor resistance in BRAF V600E-mutated melanomas. Mol Cancer Ther 7(9): 2876-2883

Schwartz GK, Robertson S, Shen A, Wang E, Pace L, Dials HD, Mendelson D, Shannon P, Gordon M (2009) A phase-I study of XL281, a selective oral RAF kinase inhibitor, in patients with advanced solid tumors. J Clin Oncol 27: 15s (abstract 3513)

Thomas NE (2006) BRAF somatic mutations in malignant melanoma and melanocytic naevi. Melanoma Res 16(2): $97-103$

Thomas NE, Edmiston SN, Alexander A, Millikan RC, Groben PA, Hao H, Tolbert D, Berwick M, Busam K, Begg CB, Mattingly D, Ollila DW, Tse CK, Hummer A, Lee-Taylor J, Conway K (2007) Number of Nevi and Early-Life ambient UV exposure are associated with BRAF-mutant melanoma. Cancer Epidemiol Biomarkers Prev 16(5): 991 - 997

Thompson JF, Scolyer RA, Kefford RF (2005) Cutaneous melanoma. Lancet 365(9460): $687-701$

Tsao H, Goel V, Wu H, Yang G, Haluska FG (2004) Genetic interaction between NRAS, and BRAF mutations and PTEN/MMAC1 inactivation in melanoma. J Invest Dermatol 122: $337-341$

Ugurel S, Thirumaran RK, Bloethner S, Gast A, Sucker A, Mueller-Berghaus J, Rittgen W, Hemminki K, Becker JC, Kumar R, Schadendorf D (2007) B-RAF and N-RAS mutations are preserved during short time in vitro propagation and differentially impact prognosis. PLoS ONE 2(2): e236

Wan PTC, Garnett MJ, Roe SM, Lee S, Niculescu-Duvaz D, Good VM, Jones CM, Marshall CJ, Springer CJ, Barford D, Marais R, Cancer Genome Project (2004) Mechanism of activation of the RAF-ERK signaling pathway by oncogenic mutations of B-RAF. Cell 116(6): $855-867$ 